\title{
Hospitalist and Internal Medicine Leaders' Perspectives of Early Discharge Challenges at Academic Medical Centers
}

\author{
Hemali Patel, MD*, Margaret C. Fang, MD, MPH², Michelle Mourad, MD², Adrienne Green, MD², \\ Robert M. Wachter, MD², Ryan D. Murphy, MD³, James D. Harrison, PhD²
}

${ }^{1}$ Division of General Internal Medicine, Department of Medicine, Hospital Medicine Group, University of Colorado Denver; 2 Division of Hospital Medicine, Department of Medicine, University of California, San Francisco; ${ }^{3}$ Division of General Internal Medicine, Department of Medicine, School of Medicine, University of Utah, Salt Lake City.

Improving early discharges may improve patient flow and increase hospital capacity. We conducted a national survey of academic medical centers addressing the prevalence, importance, and effectiveness of early-discharge initiatives. We assembled a list of hospitalist and general internal medicine leaders at 115 US-based academic medical centers. We emailed each institutional representative a 30 -item online survey regarding early-discharge initiatives. The survey included questions on discharge prioritization, the prevalence and effectiveness of early-discharge initiatives, and barriers to implementation. We received 61 responses from 115 institutions (53\% response rate). Forty-seven (77\%) "strongly agreed" or "agreed" that early discharge was a priority. "Discharge by noon" was the most cited goal ( $n=23 ; 38 \%$ ) followed by "no set time but overall goal for improvement" $(n=13 ; 21 \%)$.
The majority of respondents reported early discharge as more important than obtaining translators for non-Englishspeaking patients and equally important as reducing 30 day readmissions and improving patient satisfaction. The most commonly reported factors delaying discharge were availability of postacute care beds $(n=48 ; 79 \%)$ and patient-related transport complications $(n=44 ; 72 \%)$. The most effective early discharge initiatives reported involved changes to the rounding process, such as preemptive identification and early preparation of discharge paperwork $(n=34 ; 56 \%)$ and communication with patients about anticipated discharge $(n=29 ; 48 \%)$. There is a strong interest in increasing early discharges in an effort to improve hospital throughput and patient flow. Journal of Hospital Medicine 2018;13:388-391. Published online first December 6, 2017. ( 2018 Society of Hospital Medicine
T he discharge process is a critical bottleneck for efficient patient flow through the hospital. Delayed discharges translate into delays in admissions and other patient transitions, often leading to excess costs, $\mathrm{pa}$ tient dissatisfaction, and even patient harm. ${ }^{1-3}$ The emergency department is particularly impacted by these delays; bottlenecks there lead to overcrowding, increased overall hospital length of stay, and increased risks for bad outcomes during hospitalization. ${ }^{2}$

Academic medical centers in particular may struggle with delayed discharges. In a typical teaching hospital, a team composed of an attending physician and housestaff share responsibility for determining the discharge plan. Additionally, clinical teaching activities may affect the process and quality of discharge. ${ }^{4-6}$

\footnotetext{
*Address for correspondence: Hemali Patel, MD, 12401 E. 17th Ave, Suite 450B, Mail Stop F-782, Aurora, CO 80045; Telephone: 720-848-4289; Fax: 720848-4293; E-mail: Hemali.Patel@ucdenver.edu

Additional Supporting Information may be found in the online version of this article.
}

Received: April 25, 2017; Revised: August 22, 2017;

Accepted: August 23, 2017

(C) 2018 Society of Hospital Medicine DOI 10.12788/jhm.2885
The prevalence and causes of delayed discharges vary greatly. 7. $^{-9}$ To improve efficiency around discharge, many hospitals have launched initiatives designed to discharge patients earlier in the day, including goal setting ("discharge by noon"), scheduling discharge appointments, and using quality-improvement methods, such as Lean Methodology (LEAN), to remove inefficiencies within discharge processes. ${ }^{10-12}$ However, there are few data on the prevalence and effectiveness of different strategies.

The aim of this study was to survey academic hospitalist and general internal medicine physician leaders to elicit their perspectives on the factors contributing to discharge timing and the relative importance and effectiveness of early-discharge initiatives.

\section{METHODS}

\section{Study Design, Participants, and Oversight}

We obtained a list of 115 university-affiliated hospitals associated with a residency program and, in most cases, a medical school from Vizient Inc. (formerly University HealthSystem Consortium), an alliance of academic medical centers and affiliated hospitals. Each member institution submits clinical data to allow for the benchmarking of outcomes to drive transparency and quality improvement. ${ }^{13}$ More than $95 \%$ of the nation's academic medical centers and affiliated hospitals participate in this collaborative. Vizient works with members but does not set nor promote quality metrics, such as discharge timeliness. 
E-mail addresses for hospital medicine physician leaders (eg, division chief) of major academic medical centers were obtained from each institution via publicly available data (eg, the institution's website). When an institution did not have a hospital medicine section, we identified the division chief of general internal medicine. The University of California, San Francisco Institutional Review Board approved this study.

\section{Survey Development and Domains}

We developed a 30-item survey to evaluate 5 main domains of interest: current discharge practices, degree of prioritization of early discharge on the inpatient service, barriers to timely discharge, prevalence and perceived effectiveness of implemented early-discharge initiatives, and barriers to implementation of early-discharge initiatives.

Respondents were first asked to identify their institutions' goals for discharge time. They were then asked to compare the priority of early-discharge initiatives to other departmental quality-improvement initiatives, such as reducing 30-day readmissions, improving interpreter use, and improving patient satisfaction. Next, respondents were asked to estimate the degree to which clinical or patient factors contributed to delays in discharge. Respondents were then asked whether specific early-discharge initiatives, such as changes to rounding practices or communication interventions, were implemented at their institutions and, if so, the perceived effectiveness of these initiatives at meeting discharge targets. We piloted the questions locally with physicians and researchers prior to finalizing the survey.

\section{Data Collection}

We sent surveys via an online platform (Research Electronic Data Capture). ${ }^{14}$ Nonresponders were sent two e-mail reminders and then a follow-up telephone call asking them to complete the survey. Only 1 survey per academic medical center was collected. Any respondent who completed the survey within 2 weeks of receiving it was entered to win a Kindle Fire.

\section{Data Analysis}

We summarized survey responses using descriptive statistics. Analysis was completed in IBM SPSS version 22 (Armonk, NY).

\section{RESULTS}

Survey Respondent and Institutional Characteristics Of the 115 institutions surveyed, we received 61 responses (response rate of $53 \%$ ), with 39 (64\%) respondents from divisions of hospital medicine and 22 (36\%) from divisions of general internal medicine. A majority $(n=53 ; 87 \%)$ stated their medicine services have a combination of teaching (with residents) and nonteaching (without residents) teams. Thirty-nine (64\%) reported having daily multidisciplinary rounds.

\section{Early Discharge as a Priority}

Forty-seven (77\%) institutional representatives strongly agreed or agreed that early discharge was a priority, with discharge by noon being the most common target time $(n=23 ; 38 \%)$. Thirty $(50 \%)$ respondents rated early discharge as more important
TABLE 1. Factors Perceived to "Always" or "Often" Cause Discharge Delays at Academic Medical Centers $(\mathrm{n}=61)^{\mathrm{a}}$

\begin{tabular}{ll}
\hline Factor & $\mathbf{n}(\%)$ \\
\hline Clinical care & $27(44)$ \\
Pending consults, specialist recommendations & $21(34)$ \\
Pending clinical care (eg, PICC not placed) & $10(16)$ \\
New clinical results changing discharge plan & \\
\hline External factors & $48(79)$ \\
\hline Logistical difficulties (eg, SNF bed unavailable or transport delayed) & $29(48)$ \\
\hline Patient factors & $44(72)$ \\
Patient preference to stay & $38(62)$ \\
Patient-related transport issues & $13(21)$ \\
\hline Workflow & \\
Busy case managers, competing primary team priorities & \\
\hline Medical education demands of providers (eg, teaching or clinics) & \\
\hline a Missing data from participants who did not answer this question are excluded from N. \\
NOTE: Abbreviations: PICC, peripherally inserted central catheter; SNF, skilled nursing
\end{tabular}

than improving interpreter use for non-English-speaking patients and equally important as reducing 30-day readmissions $(n=29 ; 48 \%$ ) and improving patient satisfaction ( $n=27 ; 44 \%$ ).

\section{Factors Delaying Discharge}

The most common factors perceived as delaying discharge were considered external to the hospital, such as postacute care bed availability or scheduled (eg, ambulance) transport delays ( $n=48 ; 79 \%$ ), followed by patient factors such as patient transport issues ( $n=44 ; 72 \%$ ). Less commonly reported were workflow issues, such as competing primary team priorities or case manager bandwidth ( $n=38 ; 62 \%$; Table 1 ).

\section{Initiatives to Improve Discharge}

The most commonly implemented initiatives perceived as effective at improving discharge times were the preemptive identification of early discharges to plan discharge paperwork ( $n=34 ; 56 \%$ ), communication with patients about anticipated discharge time on the day prior to discharge ( $n=29 ; 48 \%$ ), and the implementation of additional rounds between physician teams and case managers specifically around discharge planning ( $n=28 ; 46 \%$ ). Initiatives not commonly implemented included regular audit of and feedback on discharge times to providers and teams ( $n=21 ; 34 \%)$, the use of a discharge readiness checklist ( $n=26 ; 43 \%)$, incentives such as bonuses or penalties ( $n=37 ; 61 \%$ ), the use of a whiteboard to indicate discharge times ( $n=23 ; 38 \%$ ), and dedicated quality-improvement approaches such as LEAN ( $n=37 ; 61 \%$; Table 2$)$.

\section{DISCUSSION}

Our study suggests early discharge for medicine patients is a priority among academic institutions. Hospitalist and gener- 
TABLE 2. Implementation and Perceived Effectiveness of Early Discharge Initiatives at 61 Academic Medical Centers ${ }^{\text {a }}$

\begin{tabular}{|c|c|c|}
\hline Initiative & "Effective" or "Very Effective" & Not Attempted \\
\hline Communication with patients about their anticipated discharge time on prior day & $29(48)$ & $10(16)$ \\
\hline Additional rounds with teams and/or case managers specifically focused on discharge planning & $28(46)$ & $11(18)$ \\
\hline Promoting discharge as a divisional priority & $22(36)$ & $4(7)$ \\
\hline Regular audit and feedback discharge times to providers and teams & $15(25)$ & $21(34)$ \\
\hline Use of discharge readiness checklist & $13(21)$ & $26(43)$ \\
\hline
\end{tabular}

a Missing data from participants who did not answer this question are excluded from $\mathrm{N}$. NOTE: Abbreviation:

al internal medicine physician leaders in our study generally attributed delayed discharges to external factors, particularly unavailability of postacute care facilities and transportation delays. Having issues with finding postacute care placements is consistent with previous findings by Selker et al..$^{15}$ and Carey et al. ${ }^{8}$ This is despite the 20-year difference between Selker et al.'s study and the current study, reflecting a continued opportunity for improvement, including stronger partnerships with local and regional postacute care facilities to expedite care transition and stronger discharge-planning efforts early in the admission process. Efforts in postacute care placement may be particularly important for Medicaid-insured and uninsured patients.

Our responders, hospitalist and internal medicine physician leaders, did not perceive the additional responsibilities of teaching and supervising trainees to be factors that significantly delayed patient discharge. This is in contrast to previous studies, which attributed delays in discharge to prolonged clinical decision-making related to teaching and supervision. ${ }^{4-6,8}$ This discrepancy may be due to the fact that we only surveyed single physician leaders at each institution and not residents. Our finding warrants further investigation to understand the degree to which resident skills may impact discharge planning and processes.

Institutions represented in our study have attempted a variety of initiatives promoting earlier discharge, with varying levels of perceived success. Initiatives perceived to be the most effective by hospital leaders centered on two main areas: (1) changing individual provider practice and (2) anticipatory discharge preparation. Interestingly, this is in discordance with the main factors labeled as causing delays in discharges, such as obtaining postacute care beds, busy case managers, and competing demands on primary teams. We hypothesize this may be because such changes require organization- or system-level changes and are perceived as more arduous than changes at the individual level. In addition, changes to individual provider behavior may be more cost- and time-effective than more systemic initiatives.

Our findings are consistent with the work published by Wertheimer and colleagues, ${ }^{11}$ who show that additional afternoon interdisciplinary rounds can help identify patients who may be discharged before noon the next day. In their study, identifying such patients in advance improved the overall early-discharge rate the following day.

Our findings should be interpreted in light of several limitations. Our survey only considers the perspectives of hospitalist and general internal medicine physician leaders at academic medical centers that are part of the Vizient Inc. collaborative. They do not represent all academic or community-based medical centers. Although the perceived effectiveness of some initiatives was high, we did not collect empirical data to support these claims or to determine which initiative had the greatest relative impact on discharge timeliness. Lastly, we did not obtain resident, nursing, or case manager perspectives on discharge practices. Given their roles as frontline providers, we may have missed these alternative perspectives.

Our study shows there is a strong interest in increasing early discharges in an effort to improve hospital throughput and patient flow.

\section{Acknowledgments}

The authors thank all participants who completed the survey and Danielle Carrier at Vizient Inc. (formally University HealthSystem Consortium) for her assistance in obtaining data. 
Disclosures: Hemali Patel, Margaret Fang, Michelle Mourad, Adrienne Green, Ryan Murphy, and James Harrison report no conflicts of interest. At the time the research was conducted, Robert Wachter reported that he is a member of the Lucian Leape Institute at the National Patient Safety Foundation (no compensation except travel expenses); recently chaired an advisory board to England's National Health Service (NHS) reviewing the NHS's digital health strategy (no compensation except travel expenses); has a contract with UCSF from the Agency for Healthcare Research and Quality to edit a patient-safety website; receives compensation from John Wiley \& Sons for writing a blog; receives royalties from

\section{References}

1. Khanna S, Boyle J, Good N, Lind J. Impact of admission and discharge peak times on hospital overcrowding. Stud Health Technol Inform. 2011;168:82-88.

2. White $B A$, Biddinger PD, Chang Y, Grabowski B, Carignan S, Brown DFM. Boarding Inpatients in the Emergency Department Increases Discharged Patient Length of Stay. J Emerg Med. 2013;44(1):230-235. doi:10.1016/j. jemermed.2012.05.007

3. Derlet RW, Richards JR. Overcrowding in the nation's emergency departments: complex causes and disturbing effects. Ann Emerg Med. 2000;35(1):63-68

4. da Silva SA, Valácio RA, Botelho FC, Amaral CFS. Reasons for discharge delays in teaching hospitals. Rev Saúde Pública. 2014;48(2):314-321. doi:10.1590/S0034-8910.2014048004971.

5. Greysen SR, Schiliro D, Horwitz LI, Curry L, Bradley EH. "Out of Sight, Out of Mind": Housestaff Perceptions of Quality-Limiting Factors in Discharge Care at Teaching Hospitals. J Hosp Med Off Publ Soc Hosp Med. 2012;7(5):376381. doi:10.1002/jhm.1928.

6. Goldman J, Reeves S, Wu R, Silver I, MacMillan K, Kitto S. Medical Residents and Interprofessional Interactions in Discharge: An Ethnographic Exploration of Factors That Affect Negotiation. J Gen Intern Med. 2015;30(10):14541460. doi:10.1007/s11606-015-3306-6.

7. Okoniewska B, Santana MJ, Groshaus H, et al. Barriers to discharge in an acute care medical teaching unit: a qualitative analysis of health providers' perceptions. J Multidiscip Healthc. 2015;8:83-89. doi:10.2147/JMDH.S72633.

8. Carey MR, Sheth H, Scott Braithwaite R. A Prospective Study of Reasons for Prolonged Hospitalizations on a General Medicine Teaching Service. J Gen
Lippincott Williams \& Wilkins and McGraw-Hill Education for writing and/or editing several books; receives stock options for serving on the board of Acuity Medical Management Systems; receives a yearly stipend for serving on the board of The Doctors Company; serves on the scientific advisory boards for amino.com, PatientSafe Solutions Inc., Twine, and EarlySense (for which he receives stock options); has a small royalty stake in CareWeb, a hospital communication tool developed at UCSF; and holds the Marc and Lynne Benioff Endowed Chair in Hospital Medicine and the Holly Smith Distinguished Professorship in Science and Medicine at UCSF.

Intern Med. 2005;20(2):108-115. doi:10.1111/j.1525-1497.2005.40269.x.

9. Kim CS, Hart AL, Paretti RF, et al. Excess Hospitalization Days in an Academic Medical Center: Perceptions of Hospitalists and Discharge Planners. Am J Manag Care. 2011;17(2):e34-e42. http://www.ajmc.com/journals/issue/2011/2011-2-vol17-n2/AJMC_11feb_Kim_WebX_e34to42/. Accessed on October 26, 2016.

10. Gershengorn HB, Kocher R, Factor P. Management Strategies to Effect Change in Intensive Care Units: Lessons from the World of Business. Part II. Quality-Improvement Strategies. Ann Am Thorac Soc. 2014;11(3):444-453. doi:10.1513/AnnalsATS.201311-392AS

11. Wertheimer B, Jacobs REA, Bailey M, et al. Discharge before noon: An achievable hospital goal. J Hosp Med. 2014;9(4):210-214. doi:10.1002/ jhm.2154.

12. Manning DM, Tammel KJ, Blegen RN, et al. In-room display of day and time patient is anticipated to leave hospital: a "discharge appointment." J Hosp Med. 2007;2(1):13-16. doi:10.1002/jhm.146.

13. Networks for academic medical centers. https://www.vizientinc.com/Our-networks/Networks-for-academic-medical-centers. Accessed on July 13, 2017.

14. Harris PA, Taylor R, Thielke R, Payne J, Gonzalez N, Conde JG. Research Electronic Data Capture (REDCap) - A metadata-driven methodology and workflow process for providing translational research informatics support. J Biomed Inform. 2009;42(2):377-381. doi:10.1016/j.jbi.2008.08.010.

15. Selker HP, Beshansky JR, Pauker SG, Kassirer JP. The epidemiology of delays in a teaching hospital. The development and use of a tool that detects unnecessary hospital days. Med Care. 1989;27(2):112-129. 